\title{
Titanium Oxide Nanorods pH Sensors: Comparison between Voltammetry and Extended Gate Field Effect Transistor Measurements
}

\author{
Elidia Maria Guerra1 ${ }^{*}$, Marcelo Mulato ${ }^{2}$ \\ ${ }^{1}$ Department of Chemistry, Biotechnology and Bioprocess Engineering, Federal University of São João Del Rei, \\ Ouro Branco, Brazil \\ ${ }^{2}$ Department of Physics, São Paulo University, Ribeirão Preto, Brazil \\ Email: ${ }^{*}$ elidiaguerra@ufsj.edu.br
}

Received 6 February 2014; revised 19 March 2014; accepted 7 April 2014

Copyright (C) 2014 by authors and Scientific Research Publishing Inc.

This work is licensed under the Creative Commons Attribution International License (CC BY).

http://creativecommons.org/licenses/by/4.0/

(c) (i) Open Access

\section{Abstract}

In recent years there has increased interest in the characterization of titanium oxide nanorods for application in analytical devices. The titanium oxide nanorods (NRTiO) were obtained by hydrothermal reaction with a $\mathrm{NaOH}$ solution heated in the autoclave at $150^{\circ} \mathrm{C}$ for up to $50 \mathrm{~h}$. Experimental data indicate that the prepared nanorods consist of anatase and rutile phases, with a possible interlayer structure. The NRTiO was investigated as $\mathrm{pH}$ sensor in the $\mathrm{pH}$ range $2-12$, and the extended gate field effect transistor (EGFET) configuration presented a sensitivity of $49.6 \mathrm{mV} / \mathrm{pH}$. Voltammetric data showed a sensitivity of $47.8 \mathrm{mV} / \mathrm{pH}$. These results indicate that the material is a promising candidate for applications as an EGFET-pH sensor and as a disposable biosensor in the future.

Keywords

Titanium Oxide Nanorods, pH Sensors, EGFET, Voltammetry

\section{Introduction}

It is well known that the structure of a material influences its final properties, i.e., its characteristics depend on its structure. Many kinds of nanodimensional materials like nanowires, nanorods, nanofibers, and nanotubes

\footnotetext{
*Corresponding author.
}

How to cite this paper: Guerra, E.M. and Mulato, M. (2014) Titanium Oxide Nanorods pH Sensors: Comparison between Voltammetry and Extended Gate Field Effect Transistor Measurements. Materials Sciences and Applications, 5, 459-466. http://dx.doi.org/10.4236/msa.2014.57049 
have been extensively studied [1]-[3]. However, to explore the novel applications of functional nanostructured materials remains a challenge. The extraordinary properties of some nanostructured materials make them attractive for the fabrication of novel analytical devices that have advantages over traditional ones, for instance, low cost, simple design, selectivity, miniaturization and improved sensitivity [4]. Besides, the demand for accurate, reliable, highly sensitive $\mathrm{pH}$ and biological sensors is increasing and these sensors are advancing rapidly due to their use in different areas, such as biochemistry and industrial processes [5]. Many different types of sensors have been architected, such as those based on field effect devices, because there is a high demand for specificity. Given the large demand for specific sensors, especially those based on field effect devices, many different types of materials have been developed as sensitive films or membranes. Furthermore, the determination of $\mathrm{pH}$ values is one of the most important tasks in analytical chemistry [6]. A development in $\mathrm{pH}$ measurement has been the introduction of the ion-sensitive field effect transistor (ISFET) technology as an alternative to the glass electrode [7] [8]. The flexible shape of the extended gate structure (EGFET) is another advantage of the latter type of transistors, whose better long-term stability stems from the fact that the ions present in the chemical environment are excluded from any region close to the FET gate insulator [9]. In addition, as in the case of ISFET sensors, there are several kinds of ion-sensing films and membranes that can be applied in the $\mathrm{pH}$-sensing dielectric layers of pH-EGFET, such as ruthenium oxide [10] carbon nanotubes [11], $\mathrm{SnO}_{2}$ [12] [13], $\mathrm{ZnO}$ [14], vanadium oxide [15], the $\mathrm{V}_{2} \mathrm{O}_{5}$ xerogel [16], vanadium/tungsten mixed oxides [17] [18]. In the search for another alternative of ion-sensing membranes for use in $\mathrm{pH}$ sensors, one can point out the titanium oxide nanorods (NRTiO), which displays useful chemical, optical, and electronic properties [19]-[21], and has been synthesized in nanosized configuration such as nanoparticles, nanowires, nanotubes, nanofibers, etc. [22] [23]. Besides, the NRTiO is nontoxic, biocompatible and environmentally safe, and it should offer large surface area compared with nanoparticles [24]-[29].

As described in the literature [12] [15] [16], the EGFET consists of two parts: the sensitive part is composed of a NRTiO immobilized on the substrate, and the system is completed with a commercial MOSFET CD4007UB. This structure is easily constructed and has a lot of advantages compared with the ISFET, since it does not require the fabrication of the MOSFET.

The aim of this work is to fabricate titanium oxide nanorods, to explore the interaction of the ion-sensitive membrane with charges in solution, to find out the sensor sensitivity, and to verify its suitability as an EGFET$\mathrm{pH}$ sensor. In addition to its electrical response as a $\mathrm{pH}$ sensor, the NRTiO material was also characterized by several techniques.

\section{Experiment}

The NRTiO was synthesized by the hydrolysis method, using $1.0 \mathrm{~g}$ of commercial titania $\left(\mathrm{TiO}_{2}\right)$ nanoparticle powder (Aldrich) as the starting material. In a typical hydrolysis experiment, the $\mathrm{TiO}_{2}$ powder was processed in alkali solutions, such as $\mathrm{NaOH}(10 \mathrm{~mol} / \mathrm{L}, 80 \mathrm{~mL})$ using an autoclave, at a temperature of $150^{\circ} \mathrm{C}$, for time scales up to $50 \mathrm{~h}$. During hydrolysis, titania nanoparticles were converted into titanate nanorods. The product was neutralized, followed by filtration and drying under atmospheric conditions [26] [29].

The X-ray diffraction (XRD) data were recorded on a SIEMENS D5005 diffractometer using a graphite monochromator and the $\mathrm{CuK}_{\alpha}$ emission line (1.541 $\left.\AA, 40 \mathrm{kV}, 40 \mathrm{~mA}\right)$. To this end, samples in the film form deposited onto a glass plate were employed, and the data were collected at room temperature over the range $2^{\circ} \leq 2 \theta \leq$ $50^{\circ}$, with a resolution of $0.020^{\circ}$.

Fourier-transform infrared spectra (FTIR) were recorded from 4000 to $400 \mathrm{~cm}^{-1}$ on a Bomem MB 100 spectrometer. The samples were dispersed in $\mathrm{KBr}$ and pressed into pellets.

Scanning electron microscopy (SEM) was carried out on a ZEISS microscope EVO 50 model operating at 20 $\mathrm{kV}$. A thin gold coating $(\approx 20 \AA)$ was applied to the sample using a Sputter Coater-Balzers SCD 050 .

Voltammograms were measured using an AUTOLAB (EcoChemie) model PGSTAT30 (GPES/FRA) potentiostat/galvanostat interfaced with a computer. The conventional electrode arrangement was used, which consisted of glassy carbon as the working electrode, a platinum wire auxiliary electrode, and a saturated calomel electrode (SCE) as reference. The $\mathrm{TiO}_{2}$ nanorod was deposited on the electrode surface, approximately $5 \mu \mathrm{L}$ of the powder and dried at room temperature $\left(24^{\circ} \mathrm{C}\right)$. The supporting electrolyte was a buffer solution from $\mathrm{pH} 2$ to 12. The voltammograms at different $\mathrm{pHs}$ were obtained at a potential scanning speed of $10 \mathrm{mV} \cdot \mathrm{s}^{-1}$. All the experiments were carried out in deoxigenated solutions by bubbling $\mathrm{N}_{2}$, at room temperature.

The electrical response of the EGFET sensor was measured using solutions of various $\mathrm{pH}$ values, and the 
curves were obtained by an Agilent 34970A parameter analyzer. The electrode containing the sensing film was dipped into the buffer solution at room temperature for 5 minutes prior to the electrical measurement.

\section{Results and Discussion}

Figure 1 shows XRD patterns of the NRTiO. It is clear that the formation of anatase and rutile phases took place. The strongest peaks observed for the anatase and rutile phases were (101) $2 \theta=25.3^{\circ}$ and (110) $2 \theta=29.4^{\circ}$, respectively, indicating that NRTiO presents a crystalline structure. The presence of the typical diffraction peaks (101) in the XRD patterns of the NRTiO indicates a $d$-spacing of $0.35 \mathrm{~nm}$. It has been reported that NRTiO presents a structure containing a separation between neighboring sheets surfaces, i.e., the interspacing planes about $0.3784 \mathrm{~nm}$ [30]. Based on this observation, it is possible to estimate, from Figure 1, that the nanorod formation can be occurring. Broad and low intensity peaks suggest that the anatase and rutile phases may also contain an amorphous $\mathrm{TiO}_{2}$ phase [31]. Concerning the presence of the anatase phase, the structure is bodycentered-tetragonal [30].

The weight percent of the anatase $\left(W_{A}\right)$ and rutile $\left(W_{R}\right)$ phases in the as-synthesized samples was calculated from the XRD patterns using Equations (1) and (2), as follows [32]:

$$
\begin{gathered}
W_{R}=\frac{1}{1+0.8\left(I_{A} / I_{R}\right)} \times 100 \\
W_{A}=100-W_{R}
\end{gathered}
$$

where $I_{A}$ and $I_{R}$ are the integrated intensity of the (101) reflection of the anatase phase and the (110) reflection of the rutile phase, respectively. The phase composition of the sample was estimated Equations (1) and (2), and the result was $W_{R}=76 \%$ and $W_{A}=24 \%$.

The NRTiO was also characterized by FTIR between 4000 and $400 \mathrm{~cm}^{-1}$ and the results are presented in Figure 2. The FTIR spectrum of NRTiO displays broad, intense bands around 3300,1634 , and $1354 \mathrm{~cm}^{-1}$, as well as a low intensity band at $902 \mathrm{~cm}^{-1}$. The broad and intense band located around $3400-3000 \mathrm{~cm}^{-1}$ can be ascribed to $\mathrm{OH}$ stretching vibrations. This band indicates the presence of hydroxyl groups and huge amount of water molecules in the surface and interlayer space. The vibration around $1634 \mathrm{~cm}^{-1}$ also confirms the presence of water and can be assigned to H-O-H bending vibrations. The band around $902 \mathrm{~cm}^{-1}$ (inseted in Figure 2) represents the stretching vibration of short Ti-O bonds involving nonbridging oxygen probably coordinated with sodium ions. On the basis of the FTIR results, one can infer that the nanorods contain huge amounts of water and sodium ions present in the sample and, possibly, they are not only physically adsorbed to material, but they can also belong to the lattice [33]. When the IR spectrum of the nanorods was compared with those reported in the literature [33]-[35], the observed set of bands and the spectral features agree fairly well.

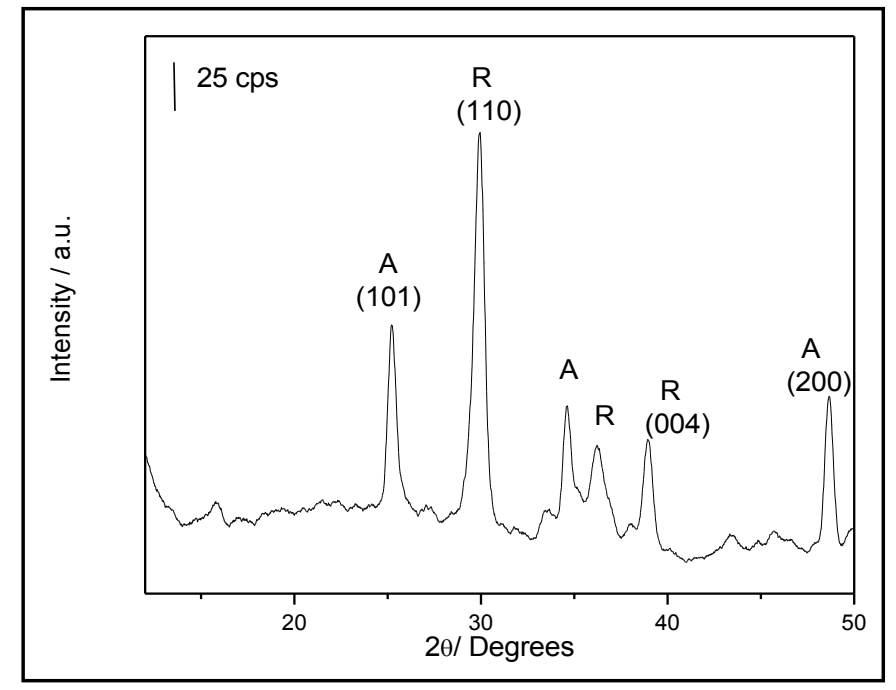

Figure 1. X-ray diffraction patterns of NRTiO. 


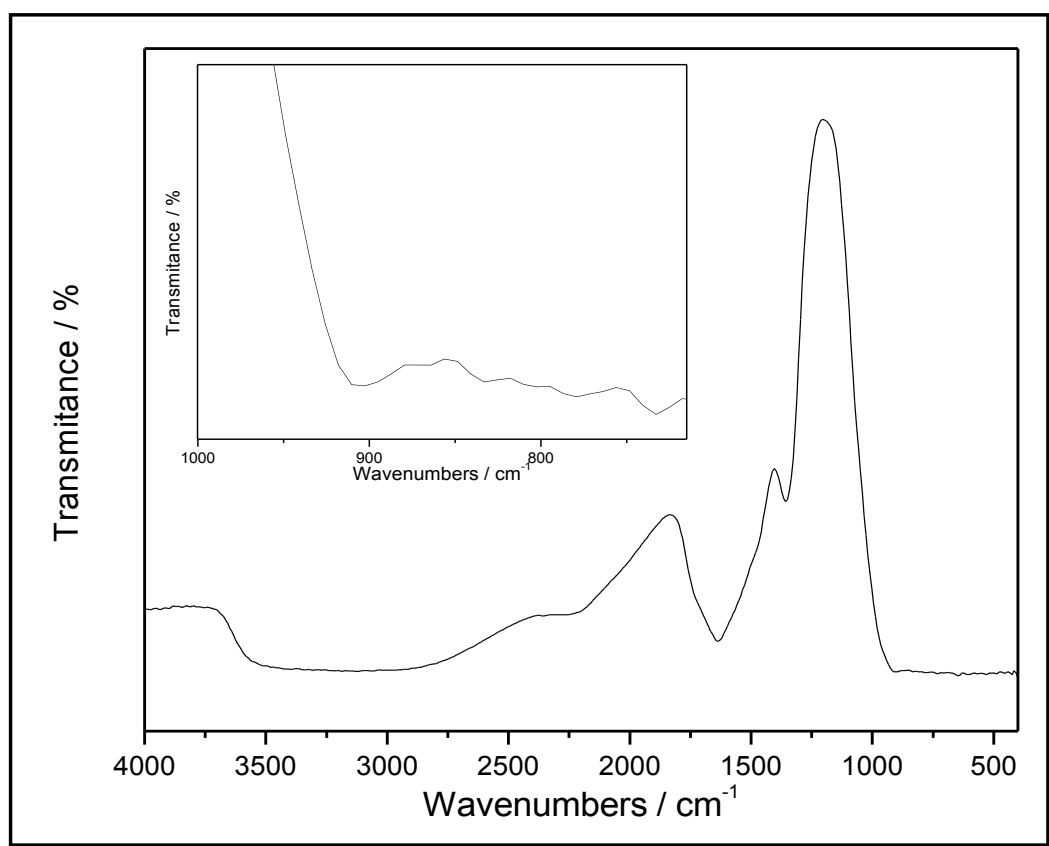

Figure 2. FTIR spectra of NRTiO.

The SEM image of the NRTiO is shown in Figure 3. As described in the literature [36], the commercial $\mathrm{TiO}_{2}$ powder particles, used as starting material, are nearly spherical in shape and have a reasonably uniform size. However, after the hydrothermal synthesis in the presence of sodium hydroxide $(\mathrm{NaOH})$, these particles undergo a delaminating process due to the attack of excess sodium cations, thus leading to two-dimensional nanosheets. The SEM results indicate that the nanorods were completely transformed into numerous stacking of wireshaped nanoparticles or into a connected nanostructure. Furthermore, as observed in Figure 3, the average size of these stacking of nanorods is $70 \mathrm{~nm}$ in diameter.

The sensitivity of the EGFET-pH sensor containing the NRTiO membrane can be obtained by measuring the relationship between drain current $\left(I_{D}\right)$ and gate-source voltage $\left(V_{G S}\right)$, which is shown in Figure 4 .

From this figure, it is possible to note that there is a clear shift toward higher voltages with increasing $\mathrm{pH}$ values. Figure 5 was produced from the data in Figure 4 and the sensitivity was estimated using $I_{D}=400 \mu \mathrm{A}$ at a $V_{D S}$ of $0.3 \mathrm{~V}$. On the basis of this $I_{D}$ value, the sensitivity was $49.6 \mathrm{mV} / \mathrm{pH}$. A variation of $10 \%$ in $\mathrm{I}_{\mathrm{D}}$ leads to only $1.5 \%$ variation in sensitivity (in the range between 350 and $450 \mu \mathrm{A}$ ). As a result, the average sensitivity is very close to the theoretical limit of $59.2 \mathrm{mV} / \mathrm{pH}$ [37]. Figure 5 shows that the EGFET exhibits good linearity, giving evidence of a constant behavior independent of the $\mathrm{pH}$ values.

Changes in the $\mathrm{pH}$ of the solution can alter the concentration of one of the species involved in the reaction, thus resulting in a shift in the redox potential. Voltammetrics studies were carried out to examine the $\mathrm{pH}$ dependence. Figure 6 shows a number of voltammograms as a function of $\mathrm{pH}$, in buffered electrolytes.

The cathodic peak region was selected, in order to ensure that the main features were preserved and to facilitate voltammogram analyses. Figure 6 shows that the potential shifts to more negative values as the $\mathrm{pH}$ increases as predicted by the Nernst equation [38]. The $\mathrm{pH}$ dependence of potential $(E)$ can also be seen in Figure 7, where $E$ is plotted against the $\mathrm{pH}$. The slope of the line is $47.8 \mathrm{mV} / \mathrm{pH}$. From the Nernst equation, the slope of the plot of $E$ vs. pH should be $59.2 \mathrm{mV} / \mathrm{pH}$, which is very close to values obtained from EGFET study. Therefore, the EGFET-pH sensor based on titanium oxide nanorods is a promising set-up and it might be suitable as a device for use in disposable sensors.

As a sensing film on a pH-EGFET configuration, the NRTiO material demonstrated a linear behavior and a high sensitivity $(49.6 \mathrm{mV} / \mathrm{pH})$ for the $\mathrm{pH}$ range $2-12$, a value $16 \%$ below the theoretical limit $(59.2 \mathrm{mV} / \mathrm{pH})$. The sensitivity was also studied by cyclic voltammetry, which led to a value of $47.8 \mathrm{mV} / \mathrm{pH}$. Both techniques give very close results. Therefore, these results suggest that the material is a good candidate as $\mathrm{pH}$ sensor and may be even further employed as a biosensor for urea and glucose detection. 


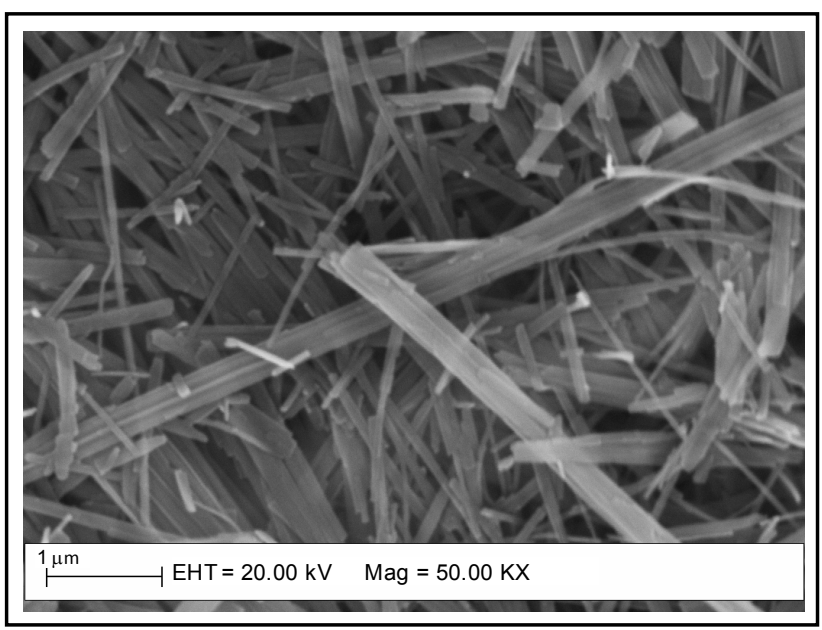

Figure 3. SEM image of NRTiO.

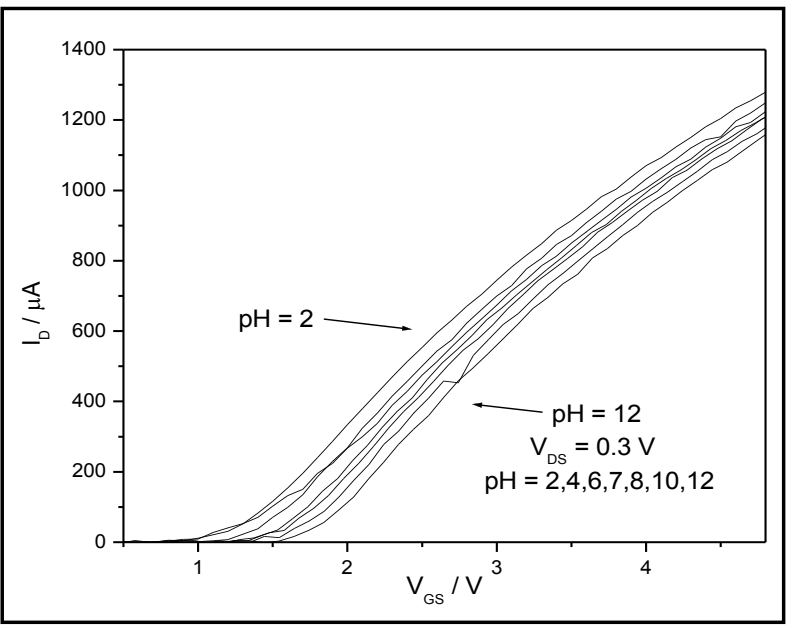

Figure 4. Response of a NRTiO-EGFET sensor in the linear region when immersed into solutions with $\mathrm{pH}$ values ranging from 2 to 12 .

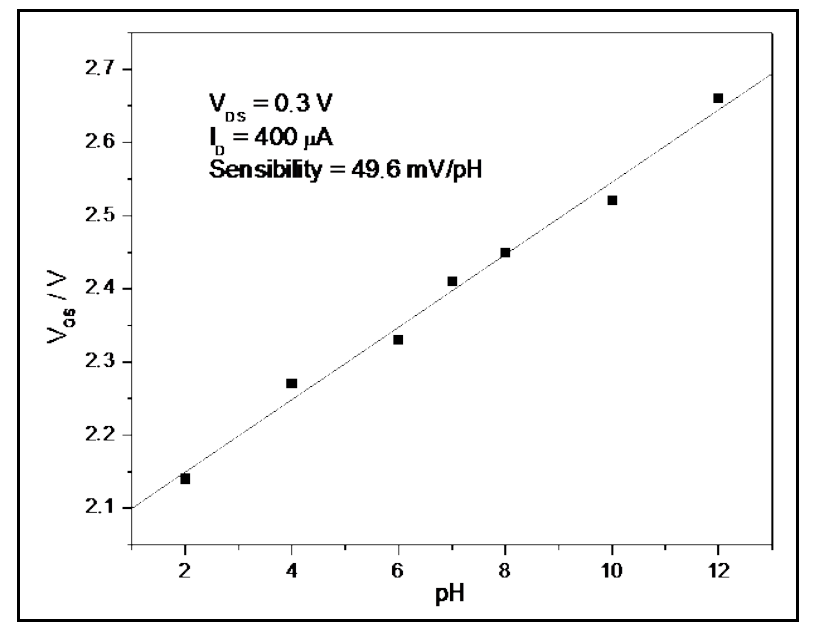

Figure 5. Sensitivity of the NRTiO-EGFET pH sensor: saturation response from $\mathrm{pH} 2$ up to $\mathrm{pH} 12$ in the linear region. 


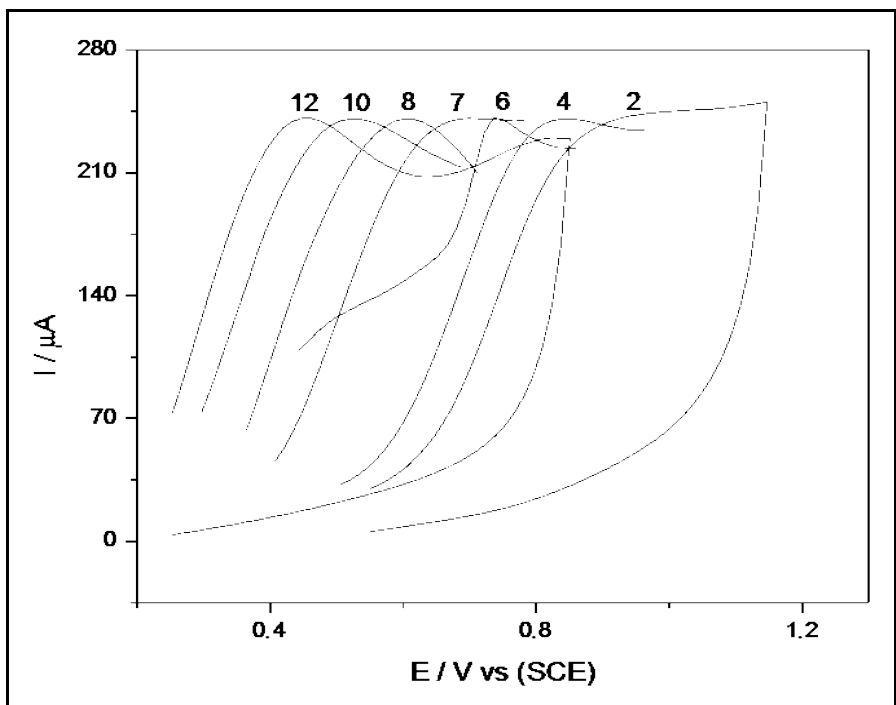

Figure 6. Voltammograms of NRTiO in buffer solution with $\mathrm{pH}$ values ranging from 2 to 12 .

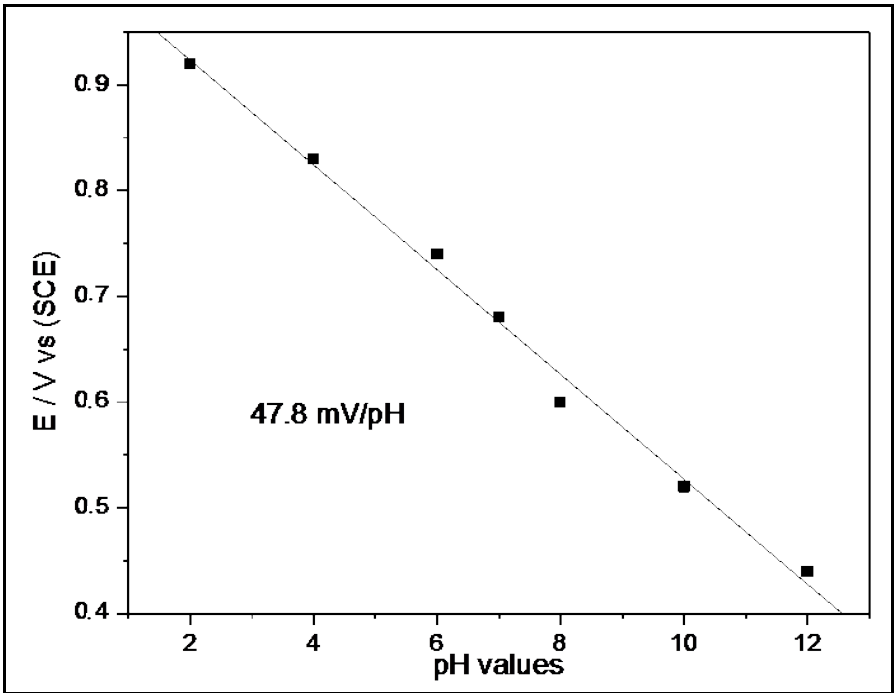

Figure 7. Potential range as a function of $\mathrm{pH}$ values for the NRTiO.

\section{Conclusion}

Titanium oxide nanorods were prepared in an autoclave at a temperature of $150^{\circ} \mathrm{C}$, for time scales up to $50 \mathrm{~h}$. The X-ray diffraction data showed that the NRTiO presents anatase and rutile phases. The SEM shows the formation of numerous stacking of nanorods with an average diameter of $70 \mathrm{~nm}$, thus indicating that the route employed was successful. As a sensing film on a pH-EGFET configuration, the NRTiO material demonstrated a linear behavior and a high sensitivity $(49.6 \mathrm{mV} / \mathrm{pH})$ for the $\mathrm{pH}$ range $2-12$, a value $16 \%$ below the theoretical limit $(59.2 \mathrm{mV} / \mathrm{pH})$. The sensitivity was also studied by cyclic voltammetry, which led to a value of $47.8 \mathrm{mV} / \mathrm{pH}$. Both techniques give very close results. Therefore, these results suggest that the material is a good candidate as a $\mathrm{pH}$ sensor and may be even further employed as a biosensor for urea and glucose detection.

\section{Acknowledgements}

The authors thank Prof. Herenilton P. Oliveira for allocation of his laboratory resources. This work was supported by FAPESP, FAPEMIG, CNPq and CAPES. 


\section{References}

[1] Miao, Z., Xu, D., Ouyang, J., Guo, G., Zhao, X. and Tang, Y. (2002) Electrochemically Induced Sol-Gel Preparation of Single-Crystalline $\mathrm{TiO}_{2}$ Nanowires. Nano Letters, 2, 717-720. http://dx.doi.org/10.1021/n1025541w

[2] Limmer, S.J., Chou, T.P. and Cao, G.Z. (2004) A Study on the Growth of $\mathrm{TiO}_{2}$ Nanorods Using Sol Electrophoresis. Journal of Material Science, 39, 895-901. http://dx.doi.org/10.1023/B:JMSC.0000012919.21763.b2

[3] Kasuga, T., Hiramatsu, M., Hoson, A., Sekino, T. and Niihara, K. (1998) Formation of Titanium Oxide Nanotube. Langmuir, 14, 3160-3163. http://dx.doi.org/10.1021/la9713816

[4] Liu, A., Wei, M., Honma, I. and Zhou, H. (2006) Biosensing Properties of Titanate Nanotube Films: Selective Detection of Dopamine in the Presence of Ascorbate and Uric Acid. Advanced Functional Materials, 16, 371-376. http://dx.doi.org/10.1002/adfm.200500202

[5] Winquist, F. and Danielsson, B. (1990) Biosensors, A Practical Approach-Semiconductor Devices, Oxford University Press, Oxford.

[6] Vonau, W. and Guth, U. (2006) pH Monitoring: A Review. Journal of Solid State Electrochemistry, 10, 746-752. http://dx.doi.org/10.1007/s10008-006-0120-4

[7] Miao, Y.Q., Chen, J.R., and Fang, K.M. (2005) New Technology for the Detection of pH. Journal Biochemical and Biophysical Methods, 63, 1-9. http://dx.doi.org/10.1016/j.jbbm.2005.02.001

[8] Bergveld, P. (2003) Thirty Years of Isfetology: What Happened in the Past 30 Years and What May Happen in the Next 30 Years. Sensors and Actuators B: Chemical, 88, 1-20. http://dx.doi.org/10.1016/S0925-4005(02)00301-5

[9] Chou, J.-C., Chiang, J.-L. and Wu, C.-L. (2005) pH and Procaine Sensing Characteristics of Extended-Gate Field-Effect Transistor Based on Indium Tin Oxide Glass. Japanese Journal Applied Physics, 44, 4838-4842. http://dx.doi.org/10.1143/JJAP.44.4838

[10] Chou, J.C. and Tzeng, D.J. (2006) Study on the Characteristics of the Ruthenium Oxide pH Electrode. Rare Metal Materials and Engineering, 35, 256-258.

[11] Silva, G.R., Matsubara, E.Y., Corio, P., Roselen, J.M. and Mulato, M. (2007) Carbon Felt/Carbon Nanotubes/Pani as pH Sensor. Materials Research Society Proceedings, Spring Meeting, 1018, EE1410-EE1411. http://dx.doi.org/10.1557/PROC-1018-EE14-10

[12] Batista, P.D., Mulato, M., Graeff, C.F.D., Fernandez, F.J.R. and Marques, F.D. (2006) $\mathrm{SnO}_{2}$ Extended Gate Field-Effect Transistor as pH Sensor. Brazilian Journal of Physics, 36, 478-481. http://dx.doi.org/10.1590/S0103-97332006000300066

[13] Liao, H.-K., Chou, J.-C., Chung, W.-Y., Sun, T.-P. and Hsiung, S.-K. (1998) Study of Amorphous Tin Oxide Thin Films for ISFET Applications. Sensors and Actuators B: Chemical, 50, 104-109. http://dx.doi.org/10.1016/S0925-4005(98)00162-2

[14] Batista, P.D. and Mulato, M. (2005) ZnO Extended-Gate Field-Effect Transistors as pH Sensors. Applied Physics Letters, 87, 143508-143510. http://dx.doi.org/10.1063/1.2084319

[15] Guerra, E.M. and Mulato, M. (2009) Synthesis and Characterization of Vanadium Oxide/Hexadecylamine Membrane and Its Application as pH-EGFET Sensor. Journal of Sol-Gel Science and Technology, 52, 315-320. http://dx.doi.org/10.1007/s10971-009-2062-7

[16] Guerra, E.M., Silva, G.R. and Mulato, M. (2009) Extended Gate Field Effect Transistor Using $\mathrm{V}_{2} \mathrm{O}_{5}$ Xerogel Sensing Membrane by Sol-Gel Method. Solid State Science, 11, 456-460. http://dx.doi.org/10.1016/j.solidstatesciences.2008.07.014

[17] Guidelli, E.J., Guerra, E.M. and Mulato, M. (2011) Ion Sensing Properties of Vanadium/Tungsten Mixed Oxides. Materials Chemistry and Physics, 125, 833-837. http://dx.doi.org/10.1016/j.matchemphys.2010.09.040

[18] Guidelli, E.J., Guerra, E.M. and Mulato, M. (2012) $\mathrm{V}_{2} \mathrm{O}_{5} / \mathrm{WO}_{3}$ Mixed Oxide Films as pH-EGFET Sensor: Sequential Re-Usage and Fabrication Volume Analysis. ECS Journal Solid State Science and Technology, 1, N39-N44. http://dx.doi.org/10.1149/2.007203jss

[19] Diebold, U. (2003) The Surface Science of Titanium Dioxide. Surface Science Reports, 48, 53-229.

[20] Zhang, Y.X., Li, G.H., Jin, Y.X., Zhang, Y., Zhang, J. and Zhang, L.D. (2002) Hydrothermal Synthesis and Photoluminescence of $\mathrm{TiO}_{2}$ Nanowires. Chemical Physics Letters, 365, 300-304. http://dx.doi.org/10.1149/2.007203jss

[21] Ross, C. (2001) Patterned Magnetic Recording Media. Annual Review of Materials Research, 31, 203-235. http://dx.doi.org/10.1146/annurev.matsci.31.1.203

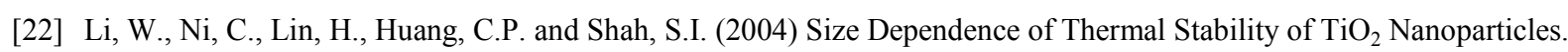
Journal of Applied Physics, 96, 6663-6668. http://dx.doi.org/10.1063/1.1807520

[23] Wang, J., Sun, J. and Bian, X. (2004) Preparation of Oriented $\mathrm{TiO}_{2}$ Nanobelts by Microemulsion Technique. Materials 
Science and Engineering: A, 379, 7-10. http://dx.doi.org/10.1016/S0921-5093(03)00625-7

[24] Du, G.H., Chen, Q., Che, R.C., Yuan, Z.Y. and Peng, L.M. (2001) Preparation and Structure Analysis of Titanium Oxide Nanotubes. Applied Physics Letters, 79, 3702-3704. http://dx.doi.org/10.1063/1.1423403

[25] Chen, Y.F., Lee, C.Y., Tao, Z.L., Yeng, M.Y. and Chiu, H.T. (2003) Titanium Disulfide Nanotubes as Hydrogen-Storage Materials. Journal of the American Chemical Society, 125, 5284-5285. http://dx.doi.org/10.1021/ja034601c

[26] Chen, Y.F., Lee, C.Y., Yeng, M.Y. and Chiu, H.T. (2003) Preparing Titanium Oxide with Various Morphologies. Materials Chemistry and Physics, 81, 39-44. http://dx.doi.org/10.1016/S0254-0584(03)00100-7

[27] Sander, M.S., Côté, M.J., Gu, W., Kile, B.M. and Tripp, C.P. (2004) Template-Assisted Fabrication of Dense, Aligned Arrays of Titania Nanotubes with Well-Controlled Dimensions on Substrates. Advanced Materials, 16, 2052-2057. http://dx.doi.org/10.1002/adma.200400446

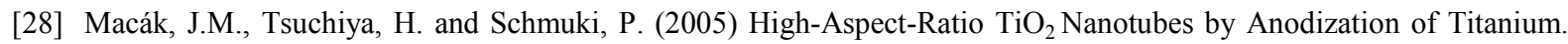
Angewandte Chemie International Edition, 44, 2100-2102. http://dx.doi.org/10.1002/anie.200462459

[29] Mor, G.K., Shankar, K., Paulose, M., Varghese, O.K. and Grimes, C.A. (2005) Enhanced Photocleavage of Water Using Titania Nanotube Arrays. Nano Letters, 5, 191-195. http://dx.doi.org/10.1021/nl048301k

[30] Yao, B.D., Chan, Y.F., Zhang, X.Y., Zhang, W.F., Yang, Z.Y. and Wang, N. (2003) Formation Mechanism of $\mathrm{TiO}_{2}$ Nanotubes. Applied Physics Letters, 82, 281-283. http://dx.doi.org/10.1063/1.1537518

[31] Juengsuwattananon, K., Jaroenworaluck, A., Panyathanmaporn, T., Jinawath, S. and Supothina, S. (2007) Effect of Water and Hydrolysis Catalyst on the Crystal Structure of Nanocrystalline $\mathrm{TiO}_{2}$ Powders Prepared by Sol-Gel Method. Physica Status Solidi (A), 204, 1751-1756. http://dx.doi.org/10.1002/pssa.200675328

[32] Spurr, R.A. and Myers, H. (1957) Quantitative Analysis of Anatase-Rutile Mixtures with an X-Ray Diffractometer. Analytical Chemistry, 29, 760-762. http://dx.doi.org/10.1021/ac60125a006

[33] Qamar, M., Yoon, C.R., Oh, H.J., Lee, N.H., Park, K., Kim, D.H., Lee, K.S., Lee, W.J. and Kim, S.J. (2008) Preparation and Photocatalytic Activity of Nanotubes Obtained from Titanium Dioxide. Catalysis Today, 131, 3-14. http://dx.doi.org/10.1016/j.cattod.2007.10.015

[34] Sauvet, A.L., Baliteau, S., Lopez, C. and Fabry, P. (2004) Synthesis and Characterization of Sodium Titanates $\mathrm{Na}_{2} \mathrm{Ti}_{3} \mathrm{O}_{7}$ and $\mathrm{Na}_{2} \mathrm{Ti}_{6} \mathrm{O}_{13}$. Journal of Solid State Chemistry, 177, 4508-4515. http://dx.doi.org/10.1016/j.jssc.2004.09.008

[35] Marchand, R., Brohan, L. and Tournoux, M. (1980) $\mathrm{TiO}_{2}$ (B) a New Form of Titanium Dioxide and the Potassium Octatitanate $\mathrm{K}_{2} \mathrm{Ti}_{8} \mathrm{O}_{17}$. Materials Research Bulletin, 15, 1129-1133. http://dx.doi.org/10.1016/0025-5408(80)90076-8

[36] Godbole, V.P., Kim, Y.S., Kim, G.S., Dar, M.A. and Shin, H.S. (2006) Synthesis of Titanate Nanotubes and Its Processing by Different Methods. Electrochimica Acta, 52, 1781-1787. http://dx.doi.org/10.1016/j.electacta.2005.12.058

[37] Temple-Boyer, P., Launay, J., Humenyuk, I., Do Conto, T., Martinez, A., Bériet, C. and Grisel, A. (2004) Study of Front-Side Connected Chemical Field Effect Transistor for Water Analysis. Microelectronics Reliability, 44, 443-447. http://dx.doi.org/10.1016/j.microrel.2003.10.001

[38] Walczak, M.M., Dryer, D.A., Jacobson, D.D., Foss, M.G. and Flynn, N.T. (1997) pH Dependent Redox Couple: An Illustration of the Nernst Equation. Journal Chemical Education, 174, 1195-1197.

http://dx.doi.org/10.1021/ed074p1195 